\title{
A study of the electrostatic charge of the coarse water droplets
}

\author{
Ondřej Bartoš $^{1^{*}}$, and Václav Peter ${ }^{1}$ \\ ${ }^{1}$ CTU in Prague, Energy Engineering Department, Technická 4, Prague 6, 166 07, Czechia
}

\begin{abstract}
The aim of this paper is introduce the results of a measurement of the electrostatic charge of water droplets during wet steam expansion. The analysis of the charge origin was done. The achieved result shows that there is not a significant charging mechanism for the fine droplets. The dependence between the specific electrical current and the amount of liquid phase collected by the probe was found. Some models were studied to determine the origin of the electrical current. Finally a model was proposed, where the el. current is generated by the disruption of thin liquid film on the surface of the probe. The charging model was later applied for the measurement of the liquid film disruption in the new wind tunnel designed for the simulation of the flow field in the steam turbines. The measurement was performed with the air as a flowing medium and two modal droplets size distribution was found.
\end{abstract}

\section{Introduction}

The presence of the liquid phase in the flowing wet steam has a very unfavourable effect on the operating characteristics and reliability of the steam turbines. Electrostatic charge could be involved in the formation of a liquid phase in the flow section of steam turbines. Knowledge of the electrostatic charge phenomena in steam turbines is therefore essential, especially on these days, this knowledge has a potential to enhance the steam turbines. The presence of electrostatic charge in the flowing steam has been proven by measurement on steam turbines $[1,2,3 \& 5]$, which showed that the charge distribution in the flow was not homogeneous and was probably influenced by the operation and chemical mode of the thermal cycle. For these reasons, the existing wind tunnel, located at the Department of Energy Engineering, Faculty of Mechanical Engineering of the Czech Technical University in Prague, was modified for research of electrostatic charge in the flowing wet steam. The measurement was made by electrostatic probe in Laval nozzle which is the part of the tunnel, where due to rapid expansion of steam, a phase change occurs, similarly as in a steam turbine. The advantage of this procedure is in a better knowledge of the steam flow field and inflow parameters in the nozzle than in a turbine measurement.

\footnotetext{
* Corresponding author: ondrej.bartos@,fs.cvut.cz
} 


\section{Measurement}

The electric current $I$ generated by the water droplets carried in the steam flow upon impact on the probe can be described by the formula:

$$
I=A . c \cdot N_{V} \cdot \int_{r k, \min }^{r k, \max } \eta_{z}\left(r_{k}\right) \cdot \alpha\left(r_{k}\right) \cdot q\left(r_{k}\right) \cdot \varphi\left(r_{k}\right) \cdot d r_{k}
$$

Where $r_{k}$ is the radius of the droplet, $A$ is the projection of the probe surface perpendicular to the flow axis, $c$ is the steam velocity, $N_{V}$ is the number density of droplets in $1 \mathrm{~m}^{3}, \eta_{\mathrm{z}}\left(\mathrm{r}_{\mathrm{k}}\right)$ is the drop impact efficiency on the probe, $\alpha\left(\mathrm{r}_{\mathrm{k}}\right)$ is the probability of the charge transfer from the droplet to the probe, $\varphi\left(\mathrm{r}_{\mathrm{k}}\right)$ distributing the droplets in the stream by the radius.

The measurement stand is shown schematically on fig. 1 as a part of the steam wind tunnel. To measure the necessary values along the nozzle axis, the nozzle is equipped with a sliding meridian. The features of the steam line and the experimental methods used for the experiment made it possible to take advantage of some simplifications in the relationship (1). It can be assumed that due to the size of the steam nozzle, the flow is one-dimensional and the distribution of droplets in the stream of wet steam is uniform. The steam flow rate was derived from the stagnation input parameters of steam $\mathrm{p}_{0}, \mathrm{~T}_{0}$ and the static pressure at the measurement site $\mathrm{p}_{\mathrm{s}}$. To determine the number and size of the water droplets in a stream of wet steam, the two wavelength method was used. It is based on the measurement of the two different wavelengths attenuation of monochromatic light when passing through a layer of wet steam. The use of this method makes it possible to assume that the liquid phase is formed in a small confined area and therefore has similar properties. It is therefore possible to introduce the assumption that the flowing mixture is monodisperse, $\varphi\left(\mathrm{r}_{\mathrm{k}}\right)=1$. The current on the electrostatic probe was measured with a micro-ammeter. The charge transfer coefficient was assumed $\alpha\left(\mathrm{r}_{\mathrm{k}}\right)=1$. Creating a capture efficiency model and a detailed description of the measurement in a steam nozzle is given in [4].

By applying relation (1) to an electrostatic probe placed in a stream of wet steam, it is possible to write a balance according to the charge conservation law (2) as shown in fig. 2.

The index $\mathrm{p}$ denotes fine droplets formed by nucleation and subsequent condensation in the steam stream and the index $\mathrm{s}$ with coarse droplets leaving the probe surface, $\mathrm{m}$ is the mass flow of the fine droplets onto the probe surface.

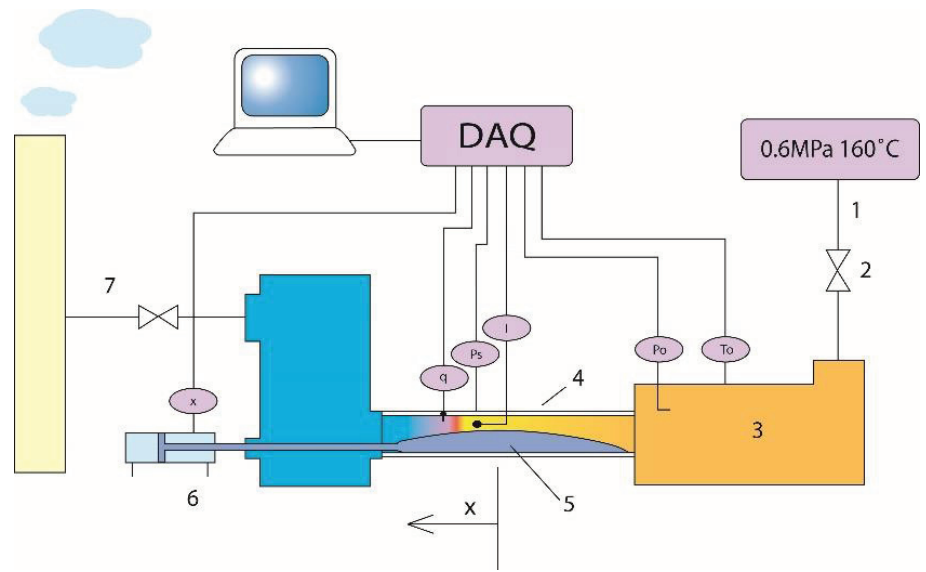

Fig. 1. Schema of the measurement in steam nozzle. 1-steam inlet, 2-gate valve and control valve, 3settling chamber, 4-nozzle, 5- meridian, 6-hydraulic cylinder, 7-outlet to atmosphere. 


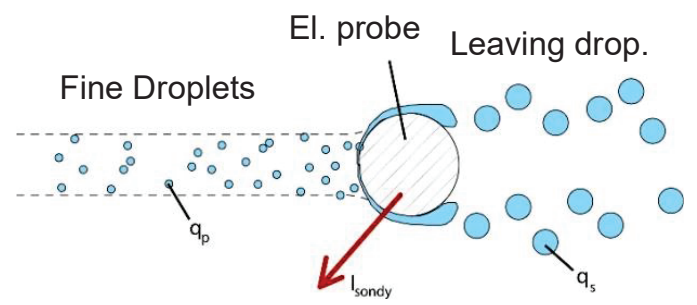

Fig. 2. The idea of distribution of electric charge between drops and probe.

$$
A c N_{V} \eta_{z(r, M a)} \bar{q}_{p}=I_{\text {sondy }}+\frac{\dot{m}}{\frac{4}{3} \pi r_{s}^{3} \rho^{\prime}} \bar{q}_{s}
$$

\section{Electrostatic probe}

Fig. 3 schematically shows the overall arrangement of the electrostatic probe. The recorded electric current is the result of the interaction between the droplets and the active part of the probe. The projection area of the active part of the probe is $1.4 \times 2 \mathrm{~mm}$. This probe can measure across the nozzle channel. The flow field influence for different positions of the active part can be considered constant for all positions of the active surface of the probe. The advantage of this probe arrangement is that it is possible to measure across the channel.

\section{Achieved data}

Measurement with the el. probe was divided into four sets of measurements, L1-L4, divided according to the stagnation pressure and temperature (Tab.1). The moving speed of the meridian was in the range of $2-3 \mathrm{~mm} / \mathrm{s}$, this velocity was determined as an optimum for eliminating the influence of the meridian leakages. The measurements were made as the meridian moved back and forth, and the values were averaged.

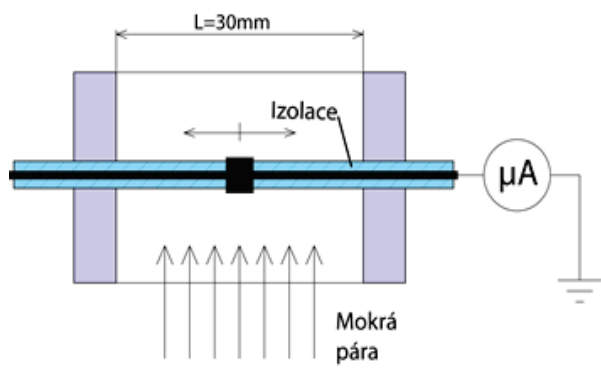

Fig. 3. Measurement schema of the electrostatic probe

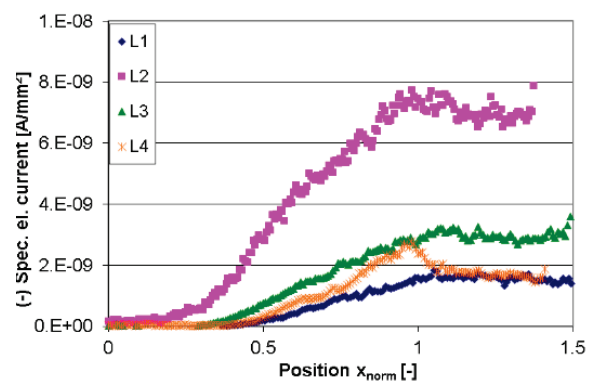

Fig. 4. current profile at the standardized coordinate 
The position coordinate was normalized so that $\boldsymbol{x}_{\text {norm }}=0$ corresponds to a light attenuation value of $5 \%$ and $\boldsymbol{x}_{\text {norm }}=1$ corresponds to the end of expansion. This method of normalizing the position coordinate is necessary because of the different steam input parameters and thus the different expansion patterns.

The specific electrical current through the probe was referenced to the unit area of the probe. This evaluation was performed for an average value across the channel, $\pm 10 \mathrm{~mm}$ from the centre of the longitudinal axis of the nozzle.

Table 1. Table of stagnation parameters

\begin{tabular}{|c|c|c|}
\hline & $\mathbf{p}_{\mathbf{0}}[\mathbf{k P a}]$ & $\mathbf{T}_{\mathbf{0}}\left[{ }^{\circ} \mathbf{C}\right]$ \\
\hline $\mathbf{L 1}$ & 248 & 155 \\
\hline $\mathbf{L 2}$ & 249 & 148 \\
\hline $\mathbf{L 3}$ & 238 & 149 \\
\hline $\mathbf{L 4}$ & 241 & 153 \\
\hline
\end{tabular}

The measurement results are shown on fig. 4, where is visible an increase of the specific electrical current in the nozzle. The el. probe measurements show that the electrical current reaches maximum values in the range of $(-1 \div-7) \cdot 10^{-9} \mathrm{~A} / \mathrm{mm}^{2}$.

\section{Data processing}

An important question, which had to be clarified, was whether there is an increase of the charge on the individual fine droplet during expansion or whether the measured increase in el. current (fig. 4) is caused by other influences. This idea is based on the notion that the electric charge is already carried by the droplets that arise during spontaneous condensation. However, it is also possible to generalize this problem and observe what parameters affect the value of the measured electric current.

All measured quantities were checked and their conformity with the profile of specific electric current measured by electrostatic probe was monitored. For comparison, it was necessary to standardize all quantities. The average value of the relevant variable around $\boldsymbol{x}_{\text {norm }}=1$ was chosen for standardization.

The best match of the measured specific electrical current was achieved when it was compared to the mass flow of the fine droplets on the probe surface according to the following formula:

$$
\dot{m}=A c N_{V} \eta_{z} \rho_{k} \frac{4}{3} \pi r_{k}^{3}
$$

The comparison was made on the basis of the standardization relation:

$$
\frac{i}{i_{0}} \approx \frac{\dot{m}}{\dot{m}_{0}}=\frac{c}{c_{0}} \frac{N_{V}}{N_{V 0}} \frac{\eta_{z}}{\eta_{z 0}} \frac{r_{k}^{3}}{r_{k 0}^{3}}
$$




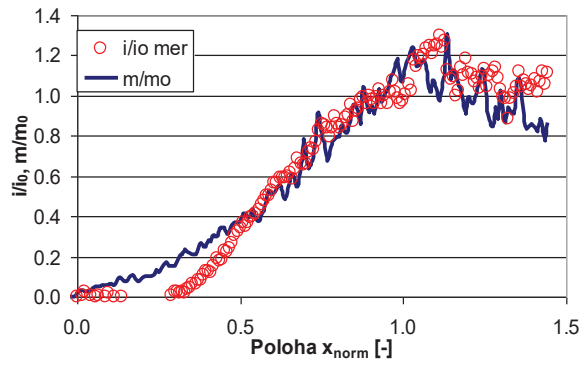

Fig. 6. Course of specific el. current and normalized mass of the liquid incident on the probe surface.

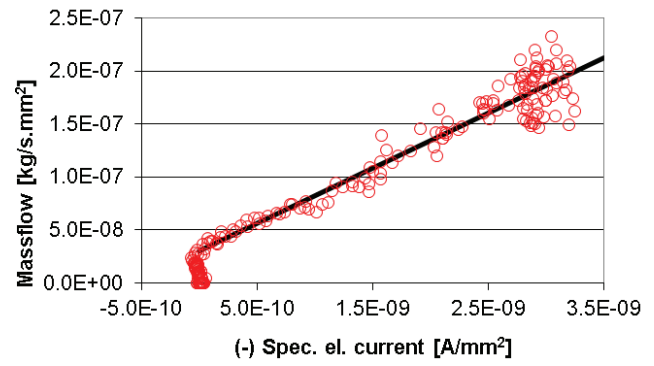

Fig. 5. Dependence between measured current and mass flow of water on the probe surface.

Figure 5 shows the waveforms of the measured normalized current and the normalized mass flow of water falling on the probe surface.

It can be seen on fig. 6 that after an initial steep increase in the zero electric current region, the linear dependence of the mass flow of the liquid phase on the surface of the electrostatic probe continues as a function of the specific electric current.

This is similar for all measurements with the electrostatic probe in a steam nozzle. The dependence was determined from all measurements by the electrostatic probe (5). The coefficients were determined as arithmetic averages and the uncertainty was determined as a standard deviation. All these values are affected by a relatively small number of data.

$$
\dot{m}=-57,21( \pm 15,48) i+3,7.10^{-8}\left( \pm 2,0.10^{-8}\right)
$$

\section{Droplets charging}

Several known methods of charging aerosols have been investigated (diffuse bipolar and unipolar, electrostatic field charging, water droplet charge dropping on the probe surface). The measured reality best described the model based on the disintegration of the water film that forms on the surface of the probe. This proposal is based on work on an electric doublelayer $[6,7 \& 10]$ for monovalent ion concentrations above $\boldsymbol{C}=1 \cdot 10^{-4} \mathrm{~mol} / \mathrm{l}$. The water that collects on the electrostatic probe is created directly during spontaneous condensation and therefore we can assume higher concentrations of chemical impurities [8] than in the bulk condensate. According to the derivation at work [9], the charge magnitude of the resulting drop is more dependent on geometric characteristics than on electrochemical properties and can be estimated approximately $\boldsymbol{q}_{s}=3,3 \cdot 10^{-15} \mathrm{C}$. Since it is obvious that the radius of entrained droplets is very important, it was determined from the Weber number:

$$
\mathrm{We}=\frac{2 \rho_{g} c^{2} r_{k}}{\sigma}
$$




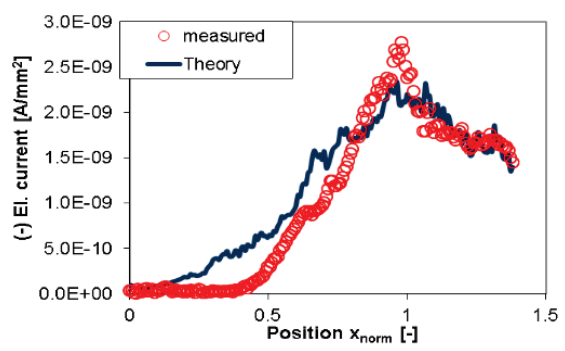

Fig. 8. Course of measured specific current and calculation for $\mathrm{We}=18$.

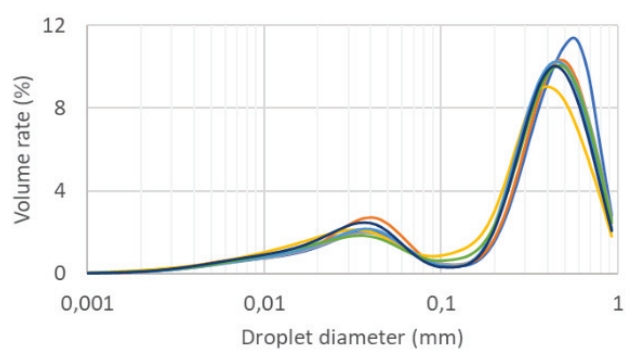

Fig. 7. Course water droplets distribution.

Where $\rho_{g}$ is the steam density, $\boldsymbol{\sigma}$ is the surface tension of the liquid. The critical Weber number was chosen according to $[8,10] \boldsymbol{W} \boldsymbol{e}_{\boldsymbol{k}}=18$. Figure 7 . shows the profile of the measured current and the electric current calculated from the theory described above.

\section{New results}

For the verification of the above mentioned results and theories a new wind tunnel was build. This tunnel is equipped with more advance measurement technic for the evaluation of the size distribution function of coarse droplets, light scattering method (Spraytec - Malvern Panalytical Ltd. ) and photogrammetric method. The tunnel is working with the air and water is pumped to the flow through the aerofoil. The results of the size distribution of the droplets are on the fig. 8. The bi-modal distribution is clearly visible. The first modus is approx. 40 $\mu \mathrm{m}$ and the second is $400 \mu \mathrm{m}$. The Weber number for the first modus is around $\boldsymbol{W e}=10$ and for the second one is more than $\boldsymbol{W e}=100$ The Weber number was determined with respect to the velocity profile in the nozzle [11,12].

The measurement of the electrical current on the electrostatic probe inserted to the flow of the drifted droplets is another parameter which could be used for the droplets identification. This measurement is following the previous work done in the steam nozzles. The charge measurement is easy, but the interpretation of the results is very complex. From this reason the profile of the measured current is presented on the fig. 9. After many simplifications one can expect the mean charge of the unique droplet app. $10^{3} \mathrm{e}$.

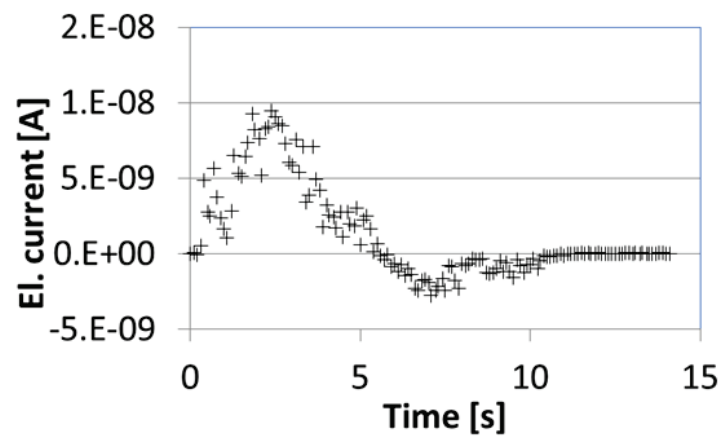

Fig. 9. El. current dep. on time 


\section{Summary}

The formation of electrostatic charge on the droplets during the expansion of steam is a very complex and still unresolved phenomenon. An important result of this work is to find a connection between the amount of water falling on the probe surface and the measured electric current. The similar knowledge was yielded from the measurement in the new wind tunnel with air. The importance of the understanding of the liquid film break up and distribution of the el. charge within these process is apparent.

We gratefully acknowledge the support by the Grant Agency of the Czech Technical University in Prague, Grant No. SGS 21/154 and National Centre for Energy TN01000007.

\section{References}

1. Cross, J.A., Electrostatics, principles, problems and applications, Adam Hilger, Bristol,1987.

2. Dooley R.B., Rieger N.F., Bakhtar F.: Studie sof elektrostatic charge effects relating to power output from steam turbine, PowerPlant Chemistry, 2005, 7(2).

3. Electrostatic charge and its influence on the condensation of steam in a turbine, EPRI, Palo Alto. CA: 2001.1001332.

4. Hinds W.C.: Aerosol technology. JohnWiley,New York,1999.

5. Iribarne, J.V., Mason, B.J., Electrification accompanying the bursting of bubbles in water and dilute aqueous solution, Transaction of Faraday society, Vol. 63, pp.22342245, 1967.

6. Lindsay, W.T., Behavior of impurities in steam turbines, Power engeneering, Vol. 5, pp. 68-72, 1975.

7. Moore, M.J., Sieverding, C.H.: Two-phase flow in turbines and separators, Theory,Instrumentation, Engineering, Hemisphere Publishing corporation, 1976.

8. O. Bartoš, X. Cai, M. Kolovratník, EPJ Web of Conferences. 2014, vol. 67, ISSN 2100-014X

9. H. Liu, Science and engineering of droplets: fundamentals and applications. Norwich, NY: Noyes Publications, c2000. ISBN 0-8155-1436-0.

10. J. Valha: Proudění mokré páry a její erozivní účinky v průtočné části parní turbíny. SVUSS, Sborník referátů, 1978

11. O. Bartoš, X. Cai and M. Kolovratník. Experimental investigation of coarse water droplets in steam turbines by the adapted photogrammetry method. In The Baumann Centenary Conference Cambridge: ISBN 978-0-903428-35-4.

12. L. Měšt’anová and $\mathrm{O}$. Bartoš. A study of the coarse water droplets formation in the nozzle. In: EFM 2018. Experimental Fluid Mechanics 2018, Praha, 2018-11-13/201811-16. Liberec: TUL, Fakulta mechatroniky a mezioborových inženýrských studií, 2018. 381-385. 